\title{
TSI uses services to fund transgenic research
}

LOS ANGELES, Calif.-TSI (Worcester, MA) might not be the first biotechnology company to use its president's home as collateral on a bank loan. But it's likely the only one to use the funds as the springboard for a 32-month shopping spree in which it acquired eight clinicaltesting and service businesses.

Starting in 1989, TSI expanded its focus on early-stage development of transgenic animals to become a significant provider of pre-clinical and clinical-testing services to other drug developers. TSI's service business is now racking up sales at an annual rate of about $\$ 60$ million and, its management cautiously predicts, it could pull all of TSI into its first-ever profit during the current fiscal-year third quarter ending March 31. The company posted an $\$ 11.3$ million loss in fiscal 1992 , which ended last June 30.

\section{Imitating Genzyme}

The home that collateralized the loan that helped put TSI into services belongs to James Sherblom, TSI's chairman, chief executive officer, and president. He also helped stretch the company's sparse finances by deferring his salary just prior to TSI's 1989 initial public offering(IPO). "When you're a very small company with very big aspirations, you have to take substantial risks," Sherblom says.

The strategy of seeking out more mundane business opportunities that could grow and eventually help fund long-term research projects was adopted from a plan that Sherblom had helped implement as chief financial officer at Genzyme (Cambridge, MA) in the mid-1980s.

Genzyme has harnessed the technical expertise in two acquired companies to improve yields-and profits-in the production of diagnostic enzymes. It then poured much of the resulting profits into a research effort to develop Ceredase, its now successful drug for treating
Gaucher's disease. Genzyme would also assemble what is currently the largest network of regional genetictesting laboratories, largely through acquisitions.

Several years later when Sherblom arrived at TSI, he saw the potential of a similar acquisition strategy. Founded in 1987 as Transgenic Sciences Inc., TSI was formed to develop transgenic technology that held the prospect of producing pharmaceutical proteins in the milk and blood of transgenic animals. "It was a great idea, but it was too high a risk and too long term a project to make it a good way to grow a company," says Sherblom.

One year into its corporate life in 1988 , TSI had raised about $\$ 350,000$ in venture-capital financing through Commonwealth Bioventures (Worcester, MA). That might have been enough funding to perhaps demonstrate the transgenic concept, but by the company's own estimates a commercial product de-

\section{Rival biotech stock indexes start slowly}

\section{The biotech} indexes's slow start is largely
due to last year's poor performance by biotech stocks.
NEW YORK - Great expectations greeted last autumn's opening of rival biotechnology stock indexes, with one listed on the American Stock Exhange (AMEX, New York) and the other on the Chicago Board Options Exchange (CBOE, Chicago, IL). The indexes allow institutional investors to hedge their bets on biotech stocks. They let individual investors participate in biotech industry growth without incurring the risk of owning any one stock. And, in so doing, they give both institutions and individuals access to perhaps the most dynamic segment of the U.S. equity market. Indeed, the CBOE index appreciated 400 percent from 1988 to 1991 , including a 100 percent return in 1991 , the biggest gain of any industry that year.

Yet the two indexes have started slowly. In November, for instance, the CBOE index saw an average of 370 option contracts traded daily, representing \$6 million of underlying stock. The index had 3,500 option contracts outstanding that month, worth $\$ 57$ million of biotech stock. November trading was even lighter on the AMEX index, as an average of 100 option contracts were traded a day, representing $\$ 1.75$ million of underlying stock. The AMEX index had 750 option contracts outstanding in November, worth $\$ 13$ million of biotech stock.

These performances were dwarfed by the performance of AMEX's pharmaceutical stock index, which opened last summer. In November, the pharmaceutical index saw an average of 630 option contracts traded daily, representing $\$ 13$ million of underlying stock. It had 8,500 option contracts outstanding that month, worth $\$ 176$ million of pharmaceutical stock.

The biotech indexes's slow start is largely due to last year's poor performance by biotech stocks. For most of the year, biotech stocks were down 50 percent from their January highs. Reflecting this decline, the CBOE index had declined 20 percent for the year by late November, while the AMEX index had dropped 23 percent. "A roaring bull market will make both indexes a lot more attractive," says Harrison Roth, senior options strategist at
Cowen \& Co. (New York).

The CBOE index has outperformed the AMEX index for a couple of reasons. CBOE currently accounts for over 90 percent of all index-options business in the U.S. "So investors are confident that CBOE can provide deep and liquid markets for the new biotech index," says Richard DuFour, CBOE's executive vice president of business development. Also, the CBOE index is more user friendly than the AMEX index. The CBOE index is weighted according to the stock prices of its component stocks, a common construction method among indexes. In the AMEX index, each component stock has an "equal dollar" weighting. This method is both unique and complicated, and investors have been slow to adopt it. The method aims to "provide a more rounded measurement of the industry as a whole and avoid dominance by any one company," says Steven Bloom, the vice president of new product development to AMEX.

Both indexes have attracted a similar mix of customers. Through No- 
rived from the technology was five to seven years and several million dollars away.

\section{New strategy}

On the conditions that the company install new management and plot a new business strategy, TSI raised another small round of venture funding in 1988 , just prior to Sherblom's arrival. It was in this cash-tight period that Sherblom pledged his home as collateral to secure a bank credit line for the company. In fact, the 1989 IPO, a unit offering that put the price of a single TSI share at about $\$ 1.25$, raised just $\$ 3$ million for the company.

The firm's new strategy-shifting from pharmaceutical development to providing products and services to help the drug-development efforts of others-took shape over the summer of 1989. TSI purchased the Mason Research Institute, the sixth largest U.S. preclinical-testing laboratory, from EG\&G (Wellesley, MA) that December for $\$ 7$ million. Half of the

vember, the AMEX index had seen 60 percent of its option-contract trades conducted by professional traders, with the remaining 40 percent of trades transacted by institutional and individual investors. On the CBOE index, professional traders accounted for 50 percent of trades through November, while other investors made up the other 50 percent of trades.

The indexes are similar in composition. The CBOE index-with a market value of $\$ 19.2$ billion at its opening-is made up of 20 stocks, 17 of which trade on the National Association of Securities Dealers Automated Quotation (NASDAQ) and three of which trade on the American Stock Exchange(ASE). The AMEX indexwith an opening market value of $\$ 16.8$ billion-is composed of 15 NASDAQ stocks. Among stocks in both indexes are Amgen (Thousand Oaks, CA), Biogen (Cambridge, MA), Centocor (Malvern, PA), Chiron (Emeryville, CA), Cytogen (Princeton, NJ), Enzon (S.Plainfield, NJ), and Gensia Pharmaceuticals (San Diego, CA). -B.J. Spalding purchase price was financed with a bank loan, again partly secured by Sherblom's home.

TSI's new game plankept research into transgenic animals, but directed it at a different goal. Transgenic research was focused on developing disease models to aid in drug development, a project that the company figured would require about five years and about $\$ 10$ million. The services business was thus anointed TSI's locomotive of nearterm growth.

With their stock rising in price in 1990, TSI went on an acquisition roll. To bolster its services in preclinical testing, it snapped up Laboratory Animal Services and the Center for Diagnostic Products, a bioreagents manufacturer. It also installed a preclinical-testing laboratory in a vacant building in Redfield, AR.

In an effort to help client companies with clinical studies, TSI acquired Health and Sciences Research for \$6 million last July. "We were handing away a few million dollars in business each year," Sherblom says. "I hate to hand away business."

TSI counts itself with Corning Laboratory Services (Coming, NY) and Applied Bioscience International (E. Millstone, NJ) as the only worldwide companies to offer drug developers a fully integrated set of services that can take a potential biological product from toxicology testing in animals through phase III clinical trials.

Although TSI is restricted by contracts from discussing client companies or their projects, Sherblom says that TSI works with all of the 10 largest pharmaceutical firms and 16 of the 25 largest biotechnology companies. "Normally, we will fill in the pieces of the program that are missing within the client company," he says. The typical client company spends only $\$ 200,000$ to $\$ 400,000$ a year at TSI. Sherblom adds, "We've tried to position ourselves so our scientists know more about disease states than the scientists in the sponsoring groups, which could prove invaluable in speeding a drug to the marketplace."

Using stock valuation as a measure, TSI's gambles appears to have paid off. Even trading recently at \$6 a share-near the low end of a recent price range that peaked at $\$ 15$ a share in November 1991-TSI carries a market valuation of about $\$ 125$ million. That compares to a roughly $\$ 7$ million valuation following its 1989 IPO. Overall, the company has raised nearly $\$ 5$ million in capital over its six-year history.

Still unclear is how successful TSI will be in developing transgenicanimal disease models, or in its plans to integrate the models into its service business. Two transgenic products-a rabbit model for AIDS and a mouse model for Alzheimer'sare expected to reach the market in 1994 and 1995, respectively. In developing such disease models, TSI faces competition from several companies, including Scios (Mountain View, CA) and SyStemix (Palo Alto, $\mathrm{CA})$, as well as several university researchers.

TSI's transgenic program is housed in a spin-off company, Exemplar. The sale of $\$ 8$ million of callable Exemplar stock in September 1991 is funding the development work, which is running at a loss of $\$ 4$ million annually. The company has been issued no patents for its work in transgenic technology, although it has picked up a few patents for reagents discovered along the way. It has also been relatively shy about publishing its transgenic research in peer-reviewed journals.

Transgenic animal models are seen as TSI's next growth locomotive, taking over as sales growth in other pre-clinical and clinical-testing services lets off steam late this decade. TSI is now turning its attention beyond transgenic models to its next big research project. "We still haven't identified our Ceredase," Sherblom says, referring to Genzyme's pharmaceutical success. Though he declined to be specific about the undertaking, Sherblom says that TSI will likely look to its core technology for ideas, possibly attempting to develop a biologic for treating a major disease.

Though he declined to be specific about the undertaking, Sherblom says that TSI will likely look to its core technology for ideas, possibly attempting to develop a biologic for treating a major disease. -Ray Potter

Ray Potter is a freelance writer in Los Angeles, CA.
While working

on transgenic

disease

models, TSI

provides pre-

clinical and

clinical-testing

services. 